\title{
Experimental study on bonding property between FRP and concrete
}

\author{
Yao Yun ${ }^{1, a}$, Zou Hao ${ }^{2, b}$ \\ ${ }^{1}$ The Engineering \& technical College of Chengdu University of technology, Leshen,China, 614007 \\ ${ }^{2}$ The Engineering \& technical College of Chengdu University of technology, Leshen,China, 614007

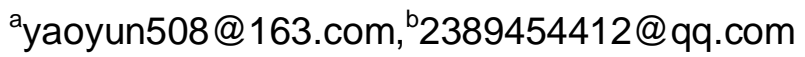

Keywords:FRP;concrete;bonding property;Slip model

Abstract:FRP is new type of composite material which substitute for reinforcing steel bar in concrete structure and can solve wear problem caused by steel bar rusting. The result of its bond behavior with concrete is one of the key technologies for its popularization and application to reinforced concrete structure.We will study the bond stress between FRP and concrete about different diameter,different buried depth,different surface forms,different types of FRP and different concrete cover thickness by pull- out test.Based on bond slip curve measured on FRP, the bond slip models existing parametersinto the model, the formulas are obtained in the bond slip curve model, compared with the bond slip curves, analyzes the advantages and disadvantages of each model.

\section{Introduction}

FRP is a kind mode of fiber composite material,it is good for light weight,high strength,corrosion resistance, anti electromagnetic performance,to replace the reinforced concrete structure; It will greatly improve performance and durability of reinforced concrete structure,to extend the service life of concrete structure, which can reduce the cost of construction and repair..It is foundation Combined between FRP and concrete for sufficient bonding force to transfer force,force and deformation of common resistance.this also is this article research content.

Early in the last ninety's century,some domestic and foreign scholar researched the bond performance of on the FRP and concrete,Pleimann ${ }^{[1]}$ research the bonding property of GFRP and AFRP respectively in 1987 and 1991 by pull-out test,modified calculation formula of the basic anchorage length.Chaalla ${ }^{[2]}$ research the bond performance of GFRP by pull-out test in 1992.In about 2000,the professor Gao Danying ${ }^{[3]}$ of Zhengzhou University and professor Xue Weichen ${ }^{[4]}$ of Shanghai Tongji University,begin to study the bond properties of FRP and concrete.Harbin Institute of Technology professor Ou Jinping ${ }^{[5]}$,carried out to compare deformation bonding properties of tendon on different shape of GFRP in 2007.

Although it has been some progress in the experimental study for the domestic and foreign scholars on FRP and concrete,but in their study, for glass fiber reinforced with ribs, And less related to the light round glass FRP and carbon fiber FRP.In this paper,it on the influence bonding performance of FRP and concrete for Different diameter,Different buried depth,Different surface form,Different types,Different thickness of concrete protective layer by thedesign 26 specimensof 5 factors.

\section{Research design and methods}

1. The experimental apparatus and test pieces

The methods of Bond anchorage test are commonly pull test and charpy test and izod test.This paperb is the pul test simply.The bond stress determinae by drawing experiment, The test load was applied by the electro-hydraulic servo universal testing machine, using uniform load.In order to eliminate effect of local compressive stress on the bond performance offRP and concrete from the loading end.It will separate thereinforcement and concrete usingin theloading end embedded length equal to $50 \mathrm{~mm}$ plastic pipe,At the same time,consideringthe anisotropic properties of FRP,The steel 
tube loaded end anchorage before the test.The specimen structure and experimental test shown in Figure 1,the typespecimen is shown in table 1.

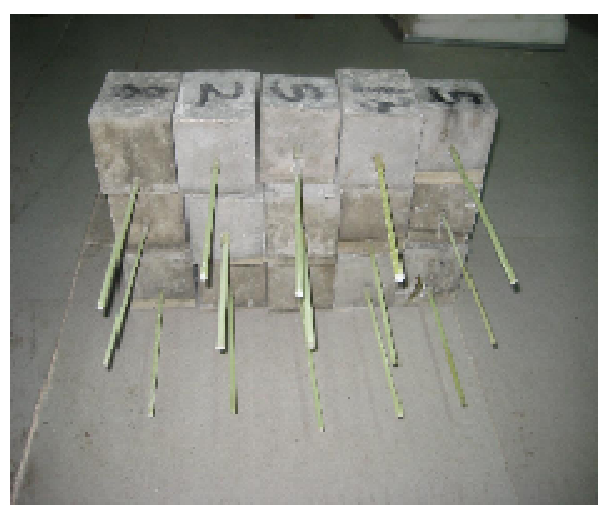

Fig 1 The experimental test

Table 1. The type of FRP concrete block

\begin{tabular}{|c|c|c|c|c|}
\hline Number & $\mathrm{D}(\mathrm{mm})$ & $\mathrm{L} / \mathrm{D}$ & $\mathrm{C} / \mathrm{D}$ & Type \\
\hline $\mathrm{S} 1$ & 5 & 10 & $\mathrm{C}=50 \mathrm{~mm}$ & Optic GFRP \\
\hline $\mathrm{S} 2$ & 7 & 10 & $\mathrm{C}=50 \mathrm{~mm}$ & Optic GFRP \\
\hline $\mathrm{S} 3$ & 10 & 10 & $\mathrm{C}=50 \mathrm{~mm}$ & Optic GFRP \\
\hline $\mathrm{S} 4$ & 12 & 10 & $\mathrm{C}=50 \mathrm{~mm}$ & Optic GFRP \\
\hline $\mathrm{S} 5$ & 7 & 5 & $\mathrm{C}=50 \mathrm{~mm}$ & Optic GFRP \\
\hline $\mathrm{S} 6$ & 7 & 15 & $\mathrm{C}=50 \mathrm{~mm}$ & Optic GFRP \\
\hline $\mathrm{S} 7$ & 7 & 20 & $\mathrm{C}=50 \mathrm{~mm}$ & Optic GFRP \\
\hline $\mathrm{S} 8$ & 7 & 10 & 2 & Optic GFRP \\
\hline $\mathrm{S} 9$ & 7 & 10 & 3 & Optic GFRP \\
\hline $\mathrm{S} 10$ & 7 & 10 & 4 & Optic GFRP \\
\hline $\mathrm{S} 11$ & 7 & 10 & 5 & Optic GFRP \\
\hline $\mathrm{S} 12$ & 7 & 10 & $\mathrm{C}=50 \mathrm{~mm}$ & Optic CFRP \\
\hline $\mathrm{S} 13$ & 7 & 10 & $\mathrm{C}=50 \mathrm{~mm}$ & Ribbed GFRP \\
\hline
\end{tabular}

2. Bond stress and result

Because of the smaller bond length,It can be assumed uniform distribution along the $\mathrm{F}$ RP embedment length.The bond strength of FRP for the definition of average value of bon $\mathrm{d}$ stress in adhesive length,namely the pull-out load(pulling force)divided by the FRP long $p$ art of the surface area.The bonding strength of FRP steel and the concrete are calculated $b$ $\mathrm{y}$ the formula:

$$
\tau=\frac{\mathrm{P}}{\pi \mathrm{DL}}
$$

Type: $\tau$ as the bond strength between FRP bars and concrete;D as FRP bar diameter;L as FRP embedment length;P as for drawing force. 


\section{Experimental results analysis}

1. The relationship between bond strength and the diameter of fiber reinforcement

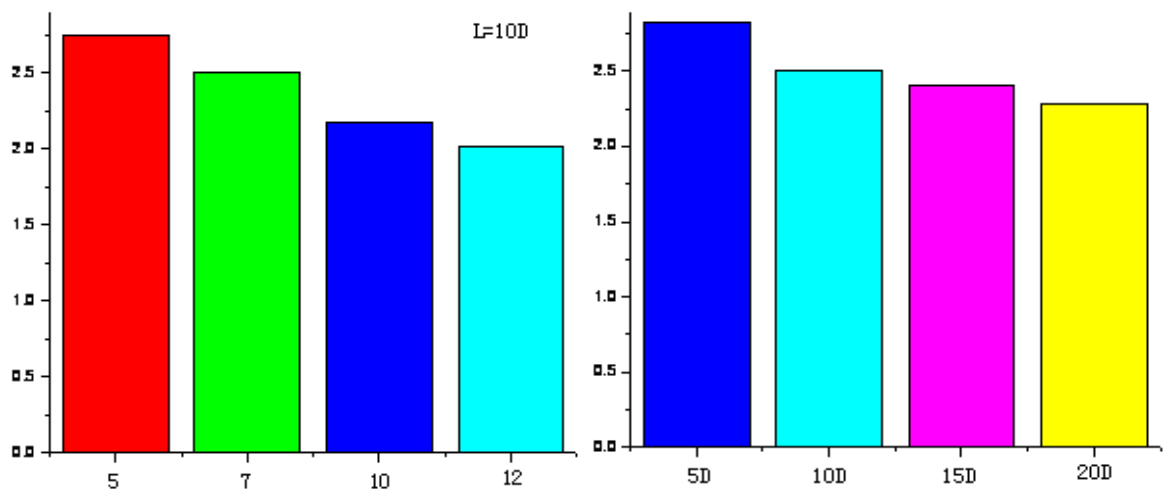

figure 2. the relationship among bond strength, the diameter of fiber reinforcement, and embedment depth

The experiment reflects (figure 2) that the longer the diameter of fiber reinforcement increases, the lower bond strength reduces. Thus, we can speculate that because the bond area of fiber reinforcement is proportional to the length of section perimeter as well as the traction is proportional to the area of section perimeter, the ratio of these two parameters indicates the corresponding bond area (4/D). As the diameter lengthens, the corresponding bond area will diminish, which is not beneficial for maximized bond strength. Accordingly, the bond strength will decreases associated with the increase of fiber reinforcement diameter.

2 the relationship between bond strength and embedment depth

The relationship between different bond strength values of fiber reinforcement and concrete as fiber reinforcement embedment length varies is shown in figure 2. The experiment reflects the bond strength decreases as embedment length increases. When the embedment length of fiber reinforcement $\mathrm{L} / \mathrm{D}>10$, the average bond strength doesn't fluctuates too much. In fact, the distribution of bond tension for fiber reinforcement and concrete is variable within the scope of embedment length, and the longer embedment length varies, the more unstable bond tension distributes. When the specimen is destroyed, the ratio of the average bond tension $\tau$ of the maximum load on the whole embedment length and the practical maximum bond tension $\tau$ max is smaller. Therefore, the average bond strength decreases as the embedment length increases.

3. the relationship between bond strength and the thickness of protection layer

The values of bond strength is based on the variation of protection layer (figure 3 ). The experiment reflects that when the value of $C / D$ is from 2.0 to 5.0, the bond strength increases as the protection layer thickens. Because of the increase of protection layer thickness, the anti-split ability of peripheral concrete intensifies, which improves the specimen's split tension and maximum bond strength. It could be also found that as the protection layer increases, the rate of the increase of bond strength slows down. So we can speculate that as further increasing the protection layer, the bond strength will tend to be stable. While pouring concrete with fiber reinforcement and steel reinforcement, there is always a requirement of minimum thickness for protection layer. Generally, the minimum thickness of protection layer for concrete beam is $35 \mathrm{~cm}$, which could improve the bond strength of reinforcement materials and concrete. In addition, $35 \mathrm{~cm}$ is 5 times longer than the diameter of reinforcement materials as usual. Such bond strength doesn't fluctuate unstably, which indirectly verifies the experimental conclusion. However, if the glass fiber reinforcement containing ribs is adopted, when the concrete protection layer becomes smaller, the specimen should be split or destroyed. By contrast, when the concrete protection layer is bigger than usual, the fiber reinforced polymer cuts off concrete along with the periphery of horizontal rib or the horizontal rib of fiber reinforced polymer is transected or pulled out instead of splitting or destroying the specimen. 


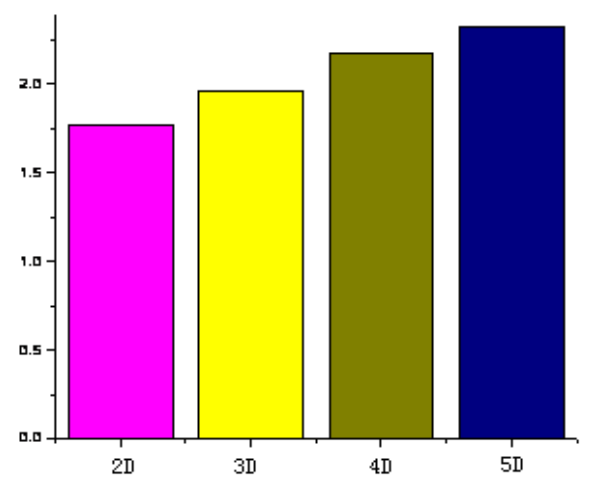

figure 3 the relationship between bond strength and the thickness of protection layer

4. the relationship between the bond strength and the classification of fiber reinforcements

According to the calculation, the average bond strength of optical circular glass fiber reinforcement is $2.50 \mathrm{MP}$ and the average bond strength of optical circular carbon fiber reinforcement is $2.56 \mathrm{MP}$. Because both bond strength is basically the same. there is no correlation between bond strength and the classification of fiber reinforcements. We can speculate that for the optical circular fiber reinforcement, at the early stage of loading, due to the small load, the free-end of fiber reinforcement doesn't drift, its bond strength with concrete is primarily provided by the chemical adhesive force. Such force is too small, which results in the free-end of fiber reinforcement drifts under the circumstance that the specimen load is not big enough. After the drift occurred, the adhesive force between fiber reinforcement and concrete disappears. Therefore, bond tension is provided by friction and mechanical interlocking force. By contrast, for optical circular fiber reinforcement, whether glass fiber reinforcement or carbon fiber reinforcement, the mechanical interlocking force is nearly zero and the friction is small as well. However, with continuously loading, the surface of reinforcement fuzzes through friction (see figure 4), which brings about the friction between fiber reinforcement and concrete is intensified and fiber reinforcement eventually is pulled out. It is obvious that the bond strength of optical circular fiber reinforcement is correlative with the degree of difficulty on the surface of reinforcement materials fuzzes caused by friction. Both fiber reinforcements are based on epoxy resin as matrix and the surface of both reinforcements fuzz produced by friction enjoys almost the same degree of difficulty, so the bond strength has nothing to do with the classification of fiber reinforcements.
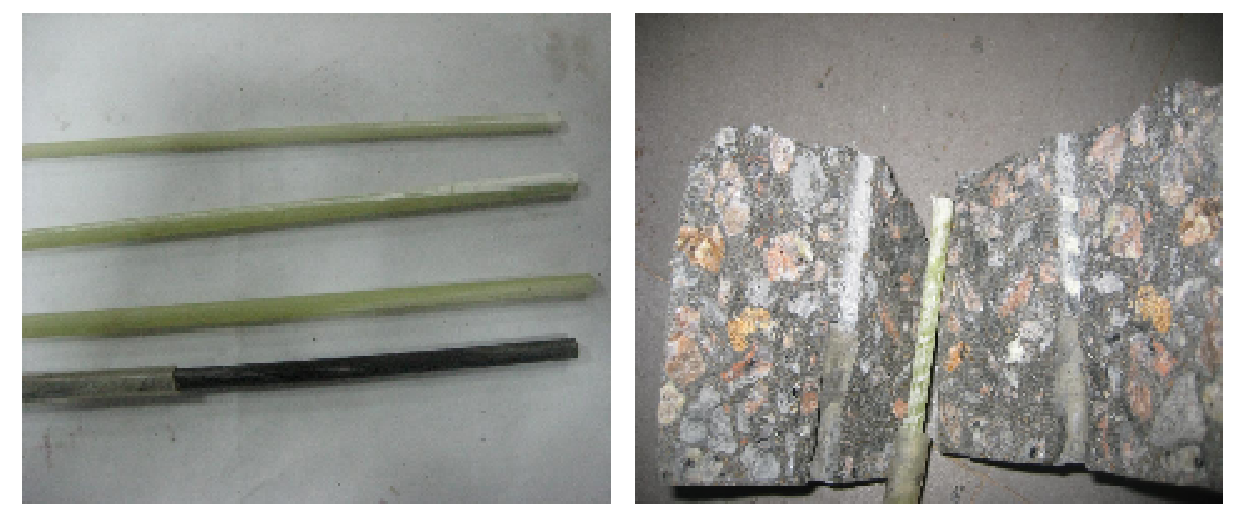

Figure 4 the surface attributes of optical circular fiber reinforcement and concrete splitting and destroying

5.the relationship between the bond strength and the surface forms of reinforcement materials

According to the calculation, the average intensity of optical circular fiber reinforcement is 2.50 MP and the cause of damage is pulling out. In the contrary, the average intensity of the glass fiber reinforcement containing ribs is $16.48 \mathrm{MP}$ and the cause of damage is concrete splitting. 
Consequently, the bond strength of fiber reinforcements is heavily impacted by the surface forms of reinforcement materials. Adding ribs on the surface of fiber reinforcements can greatly improve the bond strength of fiber reinforcements and concrete and optical circular glass fiber reinforcement is not suitable for the force-carrying reinforcement. We can speculate that both fiber reinforcements' surface have been damaged, of which the surface of optical circular glass fiber reinforcement has been scraped and fuzzed, while the glass fiber reinforcement containing ribs has been ground into power form. The surface of concrete remains powered ribs (see Figure 4). Because of destroying ribs on the surface of glass fiber reinforcement containing ribs, thus, the mechanical interlocking force between glass fiber reinforcement containing ribs and concrete will greatly increase. By contrast, the surface of optical circular glass fiber reinforcement is extremely smooth and the mechanical interlocking force with concrete is approximately zero. Consequently, the average of bond tension on glass fiber reinforcement contain ribs is much bigger than such tension on optical circular fiber reinforcement.

\section{Conclusion}

1.The average bond strength of concrete decreased with the increase of fiber diameter,.The average bond strength with the embedded length (L/D)increases, when the fiber reinforced buried long after $\mathrm{L} / \mathrm{D}>10$, the average bondstrength no more.

2.C/D in between 2.0-5.0,the average bond strength with the increase of concreteprotection layer thickness increases.It doesn't matter species of average bond strength with fiber reinforcement.

3.It is a larger effect of surface form of bond strength and reinforcement of the fiber reinforcement,in fiber reinforced ribbed surface can greatly improve the bonding strength of fiber reinforcement and concrete, light circle of glass fiber reinforcedstress bar is not easy to do.

4.It is a larger effect of surface form of bond strength and reinforcement of the fiber reinforcement,in fiber reinforced ribbed surface can greatly improve the bonding strength of fiber reinforcement and concrete, light circle of glass fiber reinforcedstress bar is not easy to do.

5.to pull out the bond slip curve damage,micro slip stage and BPE model,improved BPE model,continuous curve model are in agreement,ascending segment with the BPE model,the improved BPE model is more close to decline,section and thecontinuous curve model close.For the ribbed fibre reinforcement in residual sectiondue to mechanical bite force and the large difference between the three modelscurve.

\section{Reference:}

[1] Pleimann L G.Tension and bond pull- out tests of deformation fiberglass rods.Civil Engi neering Department, University of Arkansas,Fayettevill Ark., 1987.

[2] Chaallal O,Benmokrane B, Masmoudi R.An innovative glass- fiber composite rebar for c oncrete structures. Advanced Composite Materials in Bridges and Structures, Canadian Societ y for Civil Engineering,1992:179- 188.

[3] Gao Danying,bonding mechanism and calculating method for the anchoring length of B. Brahim.fiber reinforced polymer concrete.Journal of hydraulic engineering,2000:11.

[4] Xue Weichen,Kang Qingliang. Experimental study on bond anchorageper formance of fib er reinforced plastics.Industrial construction,1999,29(2):19-21.

[5] Hao Qingduo,Zhang Zhichun,Wang Yanlei,Ou Jinping.Bond test of different shapes of G FRP deformation reinforcement.FRP /composite,2007 second period:37-39.

[6]Zou Yongwei. Study on the bond properties of glass fiber reinforcement and concrete.Eng ineering structures. The twenty-eighth Volume 4 issue,2008,08:129 133.

[7] Xu Xinsheng,Zhang Ning,Zheng Yongfeng.Experimental study and numericalsimulation of bond performance of FRP bar and concrete.The thirty-third volume fifth issue of 2008,10:2 5 30. 